This is an electronic reprint of the original article. This reprint may differ from the original in pagination and typographic detail.

Author(s): Päivärinne, Ville; Kautiainen, Hannu; Heinonen, Ari; Kiviranta, Ilkka

Title: $\quad$ Relations between subdomains of physical activity, sedentary lifestyle and quality of life in young adult men

Year: $\quad 2018$

Version:

Please cite the original version:

Päivärinne, V., Kautiainen, H., Heinonen, A., \& Kiviranta, I. (2018). Relations between subdomains of physical activity, sedentary lifestyle and quality of life in young adult men. Scandinavian Journal of Medicine and Science in Sports, 28(4), 1389-1396. https://doi.org/10.1111/sms.13003

All material supplied via JYX is protected by copyright and other intellectual property rights, and duplication or sale of all or part of any of the repository collections is not permitted, except that material may be duplicated by you for your research use or educational purposes in electronic or print form. You must obtain permission for any other use. Electronic or print copies may not be offered, whether for sale or otherwise to anyone who is not an authorised user. 
MR VILLE PÄIVÄRINNE (Orcid ID : 0000-0002-8558-9306)

PROFESSOR ARI HEINONEN (Orcid ID : 0000-0002-3681-9953)

Article type : Original Article

\section{Relations between subdomains of physical activity, sedentary lifestyle and quality of life in young adult men}

Ville Päivärinne, $\mathrm{MSc}^{1}$, Hannu Kautiainen, $\mathrm{BA}^{2}$, Ari Heinonen, $\mathrm{PhD}^{3}$, Ilkka Kiviranta, MD, $\mathrm{PhD}^{1,4}$

1) Department of Orthopaedics and Traumatology, University of Helsinki

2) Department of General Practice and Primary Health Care, University of Helsinki

3) Department of Health Sciences, University of Jyväskylä

4) Helsinki University Hospital, Helsinki, Finland

Corresponding author: MSc Ville Päivärinne, University of Helsinki, Department of Orthopaedics and Traumatology, P.O. Box 63, FI-0014 University of Helsinki, Finland. Phone: +358504110796. Fax: +358947187481. E-mail: ville.paivarinne@helsinki.fi
ABSTRACT
Purpose: To assess the relationship between physical activity (PA) in work, transport, domestic and leisure-time domains (with sitting time included) and health-related quality of life (HRQoL) among young adult men.
Methods: The long version of IPAQ and SF-36 Health Survey were used to assess PA and HRQoL, respectively, in 1425 voluntary 20 to 40 year old Finnish male participants.
This article has been accepted for publication and undergone full peer review but has not been through the copyediting, typesetting, pagination and proofreading process, which may lead to differences between this version and the Version of Record. Please cite this article as doi: $10.1111 / \mathrm{sms} .13003$
This article is protected by copyright. All rights reserved. 
Participants were divided into tertiles (MET-h/week): Lowest tertile (<38 MET-h/week), Middle tertile (38-100 MET-h/week) and Highest tertile (>100 MET-h/week).

Results: The IPAQ domain leisure-time PA predicted positively the Physical Component Summary (PCS) $(\beta=0.11,95 \%$ CI: 0.06 to 0.16$)$ and Mental Component Summary (MCS) ( $\beta=0.11,95 \%$ CI: 0.05 to 0.16$)$ dimensions. Occupational PA predicted negative relationships in the PCS ( $\beta=-0.13,95 \%$ CI: ${ }^{-0} 0.19$ to ${ }^{-0.07)}$, and sitting time predicted negative relationships in MCS dimension ( $\beta=0.13,95 \%$ CI: ${ }^{-} 0.18$ to ${ }^{-0.07)}$. In addition, a linear relationship was found between total PA level (including sitting time) and all of the IPAQ domains $(<0.001)$. Middle tertile had the highest leisure-time PA (38\% of total PA), whereas the highest sitting time (28\%) and lowest occupational PA (8\%) were found in the lowest tertile. Highest tertile had the highest occupational PA (61\%), while the leisure-time PA was the lowest (16\%).

Conclusions: Different PA domains appear to have positive and negative relationships to mental and physical aspects of HRQoL. Relatively high leisure-time PA indicated a better HRQoL regardless of the amount of total PA, while occupational PA and higher daily sitting time related negatively to HRQoL.

Key Words: Exercise, MET, questionnaires, public health

\section{INTRODUCTION}

Physical inactivity and increasingly sedentary lifestyles have become major global public health problems associated with many chronic diseases and reduced life expectancy ${ }^{1}$. According to recent studies, $31 \%$ of the world's population is not meeting the minimum recommendations for physical activity (PA) ${ }^{2}$. From an economic point of view, in 2013 physical inactivity was responsible for a total cost of $\$ 67.5$ billion worldwide, wherein the largest proportion of economic burden originated in the public sector (ranging from $40.5 \%$ in Southeast Asia to $75.3 \%$ in Europe) ${ }^{3}$. In Finland, the majority (76\%) of adults spend most of 
their waking hours sitting, standing still or lying down, and only $32 \%$ of men between 18 to 65 years of age meet the recommended levels of PA ${ }^{4}$.

Growing evidence strongly emphasises the role of PA in health promotion, disease prevention, treatment and rehabilitation ${ }^{5}$. In addition, regular PA enhances health-related quality of life (HRQoL), that is, PA contributes to perceived well-being ${ }^{6,7}$. HRQoL is a multi-dimensional concept including physical, mental and social components of functioning ${ }^{8}$. Moreover, PA is a complex behaviour, comprising various dimensions and sub-domains such as occupational, leisure-time, housework and transport-related activity ${ }^{9}$. To date, there is limited data on the relationship between domain-specific PA and HRQoL. An increased understanding of how different PA domains associate with HRQoL can help create strategies to prevent associations between sedentary lifestyles and deleterious health effects. The aim of this study was to determine in young adult men the association between domain-specific (occupational, transportation, domestic and leisure-time) PA, including sitting time, and HRQoL.

\section{METHODS}

\section{Design and participants}

In this population-based cross-sectional study, 1425 male participants (born in 1969, 1974, 1979,1984 or 1989) were randomly selected in 2009 as a population sample from those who had performed, or discontinued military service, or had performed an alternative non-military service. Immigrants, imprisoned subjects or persons with mental disorders were excluded from the study. In the present study, we define 20 to 40 year old men as young adults ${ }^{10}$. 
Participants have given written informed consent, and the study was approved by the Coordinating Ethics Committee of the Helsinki University Hospital (Dnro 267/13/03/00/09).

\section{Questionnaire}

A questionnaire, partly based on The Finnish Health 2000 study ${ }^{11}$, was used in 2010 to record health behavioural and functional capacity, mental disorders, musculoskeletal disorders, alcohol consumption, work ability, pain and PA.

\section{Primary outcomes}

PA was measured by the validated Finnish version of the International Physical Activity Questionnaire (IPAQ) long version. IPAQ assesses detailed PA levels in four different domains (work-related activity, transport-related activity, domestic and gardening activities and leisure time activity). Each domain contains at least two levels of intensity (walking, moderate or vigorous) to provide domain-specific scores. IPAQ also assesses the time person spends sitting while at work, at home, while doing course work and during leisure time. Questions in the IPAQ require respondents to recall PA over the past 7 days. Each type of activity is weighted by its energy requirements defined in metabolic equivalent minutes per week (MET min/week). A MET score is obtained in hours/week by multiplying the MET value for the activity (3.3 for walking, 4.0 to 6.0 for moderate-intensity activity and 8.0 for vigorous-intensity activity) with duration (minutes) and frequency (days) and converted to hours. The IPAQ long form has been proven to be a valid and reliable instrument when assessing levels and patterns of PA ${ }^{12}$, and can be culturally adapted for the Finnish population ${ }^{13}$. 
Sitting question is not included as a part of PA, and it also excludes the time spent sitting during travel under the transport domain. Minutes are used to indicate the time spent sitting rather than MET-minutes. This reflects the average time an individual spends sitting per day using the following formula, wherein weekday (a) sitting minutes are multiplied by 5 weekdays and weekend (b) day sitting minutes are multiplied by 2 weekend days ${ }^{14}$ :

$$
\text { Sitting time }=(a * 5+b * 2) / 7
$$

Participants were divided into tertiles based on their total PA (MET-h/week): Lowest tertile (<38 MET-h/week), Middle tertile (38 - 100 MET-h/week) and Highest tertile (> 100 METh/week).

Participant HRQoL was assessed by the SF-36 Health Survey, which consists of eight domains measuring physical functioning. Each category is scored on a scale of 0-100, wherein 0 represents the worst overall health status and 100 the best health status ${ }^{15}$. The scales represent separate but conceptually related aspects of HRQoL; the overall level of subjective HRQoL is portrayed by the scale's score profile. The scales of physical functioning and physical role functioning reflect the respondent's self-rated capability in activities of daily living and mobility. The other scales cover emotional well-being, energy and vitality, bodily pain, general health and limitations in role functions and interaction (social functioning, emotional role functioning) ${ }^{16}$. Four scales (Physical Functioning, RolePhysical, Bodily Pain and General Health) contributed to the scoring of the Physical Component Summary (PCS), while four other scales (Vitality, Social Functioning, RoleEmotional and Mental Health) contributed to the Mental Component Summary (MCS). These two distinct summary components were aggregated using a US reference population (1990) 
for standardisation of the eight domains and for factor score coefficients. Finally, MCS and PCS scores were standardised using a mean of 50 and a standard deviation of $10^{17}$.

\section{Secondary outcomes}

Occupational status and diagnosed disorders were assessed by the Work Ability Index (WAI) 18. Alcohol-specific questions included consumption, which was estimated by daily quantity and frequency (weekly/monthly) over the past 12 months. The Finnish guidelines for highrisk alcohol consumption levels for healthy adult males are considered as more than 6 drinks at once and 23-24 drinks per week ${ }^{19}$. General pain, low back pain, lower limb pain, neck pain or upper limb pain were assessed by a numeric pain rating scale (NRS), wherein 0 refers to 'no pain' and 10 to 'worst pain imaginable' ${ }^{20}$. The NRS has been shown to be a reliable and valid instrument in assessing pain ${ }^{21}$.

\section{Statistical analysis}

The data is presented as means with standard deviations (SD), as medians with interquartile range (IQR) or as counts with percentages. Linearity across the three PA levels was tested using the Cochran-Armitage test, Cuzick test or analysis of variance (ANOVA). In the case of violation of the assumptions (e.g., non-normality), a bootstrap-type test was used. Linear regression analyses were used to identify the appropriate predictors of the physical summary or mental summary indices using standardised regression coefficients Beta $(\beta)$. The B value is a measure of how strongly each predictor variable influences the criterion (dependent) variable wherein the $\beta$ is measured in units of standard deviation. Cohen's standard for B values represent small $(0.10)$, moderate $(0.30)$ and large $(0.50)$ relationships. The normality of the variables was tested by using the Shapiro-Wilk W test. Stata 14.1, StataCorp LP (College Station, TX, USA) statistical package was used for the analysis. 


\section{RESULTS}

Forty-eight participants were excluded because of incomplete survey data. According to IPAQ ${ }^{14}$, another 99 participants were excluded because they reported a total sum of PA more than $16 \mathrm{~h}$ a day (walking, moderate or vigorous activity). The final sample consisted of 1278 male participants. Demographic and clinical characteristics of the study participants according to total PA (MET-h/week) are shown in Table 1. A linear relationship across MET tertiles was found between subjects' age, meaning that older subjects had the lowest METh/week scores.

Figure 1.

Table 1.

There was a linear relationship between accidents, general pain, low back pain and neck pain. This demonstrated that the higher the MET-h/week, the more incidents there were between the tertiles. There was also a linear relationship in the subjects' employment status between the tertiles. Inverse linear relationships were found between either being a student, unemployed, on disability pension or having mental disorders, meaning that the lower MET$\mathrm{h} /$ week, the higher the incidence was in these categories.

The PA domains expressed as MET-h/week and daily sitting time are shown in Table 2. A linear relationship was found between total PA tertiles, with sitting time included, and in all the other IPAQ domains. In the Highest tertile, the most common type of PA was 
occupational PA (mean: 3 h/week, 19 h/week and 129 h/week in tertiles, respectively) (Table 2).

Table 2.

The relative MET-h/week in IPAQ domains and average sitting time (h/day) according to tertiles are shown in Figure 2. In the Highest tertile, the relative occupational PA was highest (61\% of total PA), while the leisure-time PA was the lowest $(16 \%)$. On the other hand, the Middle tertile had the highest relative leisure-time PA (38\%), whereas highest relative sitting time (28\%) and lowest occupational PA (8\%) were found in the Lowest tertile (Figure 2.).

Figure 2.

Figure 3.

Age- and employment status-adjusted mean HRQoL are shown across the MET tertiles (Figure 3). There were statistically significant differences between the total PA tertiles and all of the HRQoL domains.

Figure 4.

The $\beta$ values are described as indicators of PCS or MCS dimensions in IPAQ domains (Figure 4.) Univariate IPAQ domains predicted moderate negative relationships between Work domain and PCS dimension $\left(\beta==^{-0.13,95 \% ~ C I: ~}{ }^{-0.19}\right.$ to ${ }^{-0.07)}$ and between Sitting domain and MCS dimension $\left(\beta=-0.13,95 \%\right.$ CI: ${ }^{-} 0.18$ to ${ }^{-0.07)}$. However, the Leisure-Time 
domain predicted moderate positive relationships in both the PCS $(\beta=0.11,95 \% \mathrm{CI}: 0.06$ to $0.16)$ and MCS ( $\beta=0.11,95 \%$ CI: 0.05 to 0.16$)$ dimensions.

\section{DISCUSSION}

The results presented here indicate a significant relationship between total PA (MET-h/week) and HRQoL dimensions in this population of healthy male subjects between 20 to 40 years of age. On the contrary, a higher sitting time was associated with greater inactivity and was negatively related to mental health, while higher occupational PA was negatively related to physical health. In addition, leisure time predicted positive physical function and mental health.

Our findings are consistent with the systematic review of Bize et al. ${ }^{6}$, which describes a strong positive association through cross-sectional studies between total PA and HRQoL in the general population of healthy adult men and women. In addition, higher total PA levels were associated with better HRQoL in various dimensions. Furthermore, a positive association between PA and HRQoL in the elderly population has also been reported ${ }^{7}$. Moreover, our findings are consistent with previous studies that reported positive relationships between leisure-time PA and Physical Summary score ${ }^{22-25}$ and Mental Summary score ${ }^{22,24,26}$ in a healthy male and female adult population. However, the information is sparse between domain-specific PA, including sitting time, and HRQoL in young adult men.

In the present study, the average daily sitting time varied between 5 to 8 hours per day, with the highest mean value in the most inactive group. There are no public health reference values for sitting time, probably because sedentary time has not been considered to be 
harmful to health until very recently ${ }^{27}$. Biswas et al. ${ }^{28}$ found that overall sedentary time or sitting time (either television or screen time) is associated with an increased incidence of cardiovascular disease, type 2 diabetes, certain types of cancer as well as all-cause mortality in adults. However, increased PA (either moderate or vigorous intensity) in older men and women seems to reduce the mortality risk associated with high sitting time, but not the risk associated with high TV-viewing time ${ }^{1}$. In addition, a low level of PA combined with high screen time is negatively associated with $\mathrm{HRQoL}^{29}$. In the present study, sitting time was not divided into leisure time, screen time, study or work-related. Presumably, behavioural aspects during screen time (such as eating and drinking) could be the factors that cause TV-viewing sitting more harmful to health than other types of sitting. Negative associations between sedentary behaviour and HRQoL have been previously reported in older adults ${ }^{30,31}$, although there is also recent evidence of a positive association of domain-specific sedentary time (reading time) and mental-based HRQoL in middle-aged adults ${ }^{29}$. Nevertheless, in our study, the Lowest tertile averaged the most daily time sitting. This indicates that due to the lack of PA, this relationship could be the most harmful to health compared to all the other tertiles.

In the present study, occupational PA related to musculoskeletal disorders, injuries or deleterious effects on health suggests that a large proportion of the subjects with these conditions were possibly involved in heavy physical labour. It has been previously shown that frequent excessive PA can result in detrimental heart conditions and cardiovascular disease $^{32}$. In addition, heavy physical labour is a significant risk factor for low back pain, accident occurrence and all-cause mortality ${ }^{33,34}$. However, Holtermann et al. ${ }^{34}$ found that higher levels of leisure-time PA decreased the risk of all-cause mortality caused by high occupational PA. In the present study, occupational PA was negatively related to the Physical Summary dimension of HRQoL, which might indicate that participants in the Highest tertile 
could face possible deleterious health symptoms in the future. Moreover, it is also possible that excessive occupational PA may explain the relatively low leisure-time PA in the Highest tertile.

A significantly lower HRQoL Vitality score and highest relative sitting time in the Lowest tertile could indicate that these subjects are less physically active, sit more on a daily basis and feel less energetic. The Lowest tertile also had the highest incidence of mental disorders; sitting time predicted a negative mental summary dimension. This observation can be explained at least in part by the higher inactivity in this group, since PA and exercise have been reported to improve physical and mental well-being ${ }^{35}$. Furthermore, low values in the work PA domain in the Lowest tertile may indicate that large proportion of these subjects were white-collar workers or vehicle operators. Riise et al. ${ }^{22}$ reported that drivers or mobile plant operators had the lowest mean scores in the SF-36 physical component summary scale. Drivers are also known to have a high risk of developing musculoskeletal disorders ${ }^{22}$. However, the present study did not demonstrate a significant association or relationship between sedentary lifestyle and physical symptoms. Different lifestyle factors, such as PA, inactivity and alcohol consumption have demonstrated importance in an elderly group of workers but not among young workers, suggesting that health problems due to an unhealthy lifestyle occur at an older age ${ }^{36}$. This may explain the lack of a linear relationship between the tertiles in diagnosed disorders. On the other hand, perceived poor health appears to predict becoming or remaining employed ${ }^{37}$, which may explain the relationship in employment status according to total PA.

A previous systematic review reported a possible association between sedentary lifestyle and PA, suggesting that sedentary behaviour could diminish the benefits of light intensity PA ${ }^{38}$. 
This association might have occurred in our study as well. In other words, the Lowest tertile might have replaced light occupational PA (e.g., standing and light walking) with sitting; this may thus also reflect the lack of leisure-time or transportation PA. On the other hand, the relatively high leisure-time PA in the Middle tertile may reflect compensating the daily sitting time with increased energy expenditure during free time ${ }^{39}$. However, the compensatory effect (or the lack thereof) could have been seen in the Lowest tertile, which may be explained by the relationship of high sitting time and low PA level. Moreover, it has been suggested that genetics may also affect activity behaviours that determine the level of PA $^{9}$. There are also findings of moderate genetic effects on SF-36 domain and summary measures ${ }^{40}$. Despite the fact that heritability was not a measured factor in our study, should the role of genetics be taken into consideration.

Our study had several strengths, such as (1) the use of validated and widely employed questionnaires, (2) the use of IPAQ long form to calculate domain-specific PA level estimations, sitting included, which has not been presented in previous studies, (3) the use of a random, homogenous sample that permitted a reliable generalisation of the study population and (4) the use of a large sample size. However, there are also limitations to our study that should be taken into consideration. Due to the cross-sectional design, determinations of causality cannot be analysed; the findings remain therefore purely hypothesis generating. Secondly, the complex nature of PA and HRQoL was investigated using self-reported questionnaires, which may result in reporting bias ${ }^{41}$. In conclusion, among young adult men, PA was significantly related to HRQoL physical and mental summary components. More specifically, leisure-time PA was positively related to physical and mental summary, while occupational PA was negatively related to physical summary and sitting time was negatively related to mental summary.

This article is protected by copyright. All rights reserved. 


\section{PERSPECTIVES}

Our study adds useful information to the body of evidence between domain specific, relative PA and HRQoL, which could assist public health efforts in promoting positive health messages and health interventions to improve lifestyles, particularly, in young adult men. The total amount of PA does not appear to be as beneficial to HRQoL as does relatively high amount of leisure-time PA. The present findings provide valuable information of negative associations in HRQoL between excessive occupational PA and daily sitting time. In contrast, relatively high leisure-time PA indicated a better HRQoL regardless of the amount of total PA. In the future studies, it will be important to assess domain-specific and relative PA, sitting time included, and not only total PA.

\section{Acknowledgments}

This study was funded by the Social Insurance Institute of Finland (ref: 16/26/2009), Scientific Board for Defence (ref: 630/70.03.01/2015, 474/70.03.00/2016) and Centre for Military Medicine. None of these had role in study design, collection, analysis and interpretation of data; in the writing of the manuscript; and in the decision to submit the manuscript for publication.

\section{Ethical approval}

The study protocol (Dnro 267/13/03/00/09) was approved by the Coordinating Ethics

Committee of the Helsinki University Hospital. Written informed consent was obtained from all participants prior to enrolment.

\section{Conflict of interests}

None.

This article is protected by copyright. All rights reserved. 


\section{References}

1. Ekelund U, Steene-Johannessen J, Brown WJ, et al. Does physical activity attenuate, or even eliminate, the detrimental association of sitting time with mortality? A harmonised meta-analysis of data from more than 1 million men and women. Lancet. 2016;388(10051):1302-1310.

2. Kohl HW,3rd, Craig CL, Lambert EV, et al. The pandemic of physical inactivity: Global action for public health. Lancet. 2012;380(9838):294-305.

3. Ding D, Lawson KD, Kolbe-Alexander TL, et al. The economic burden of physical inactivity: A global analysis of major non-communicable diseases. Lancet. 2016;388(10051):1311-1324.

4. World Health Organization. Finland-physical activity factsheet. http://www.euro.who.int/_data/assets/pdf_file/0008/288107/FINLAND-PhysicalActivity-Factsheet.pdf?ua=1. Published February 18, 2016. Accessed December 12, 2016

5. Reis RS, Salvo D, Ogilvie D, et al. Scaling up physical activity interventions worldwide: Stepping up to larger and smarter approaches to get people moving. Lancet. 2016;388(10051):1337-1348.

6. Bize R, Johnson JA, Plotnikoff RC. Physical activity level and health-related quality of life in the general adult population: A systematic review. Prev Med. 2007;45(6):401-415.

7. Vagetti GC, Barbosa Filho VC, Moreira NB, Oliveira V, Mazzardo O, Campos W. Association between physical activity and quality of life in the elderly: A systematic review, 2000-2012. Rev Bras Psiquiatr. 2014;36(1):76-88.

This article is protected by copyright. All rights reserved. 
8. Revicki DA. Health-related quality of life in the evaluation of medical therapy for chronic illness. J Fam Pract. 1989;29(4):377-380.

9. Bauman AE, Reis RS, Sallis JF, et al. Correlates of physical activity: Why are some people physically active and others not? Lancet. 2012;380(9838):258-271.

10. Boyd D, Bee H. Lifespan development. Boston, MA: Pearson Education, Inc.; 2002. 658 p.

11. Aromaa A., Koskinen S.

Health and functional capacity in Finland: Baseline results of the health 2000 health examination survey. Publications of the National Public Health Institute B12/2004, Helsinki: KTL National Public Health Institute, Finland; 2004. 171 p.

12. Hagstromer M, Oja P, Sjostrom M. The international physical activity questionnaire (IPAQ): A study of concurrent and construct validity. Public Health Nutr. 2006;9(6):755-762.

13. Craig CL, Marshall AL, Sjostrom M, et al. International physical activity questionnaire: 12-country reliability and validity. Med Sci Sports Exerc. 2003;35(8):1381-1395.

14. International Physical Activity Questionnaire team. Guidelines for data processing and analysis of the international physical activity questionnaire (IPAQ). http://www.ipaq.ki.se/scoring.pdf. Published November, 2005. Accessed November 26, 2016

15. Fayers P. Quality of life. assesment, analysis and interpretation. 2nd ed. Chichester, England: Wiley; 2000. 568 p.

This article is protected by copyright. All rights reserved. 
16. Ware JE,Jr, Kosinski M, Gandek B, et al. The factor structure of the SF-36 health survey in 10 countries: Results from the IQOLA project. International quality of life assessment. J Clin Epidemiol. 1998;51(11):1159-1165.

17. Ware JE, Kosinski M. SF-36 physical and mental health summary scales: A manual for users of version 1. 2nd ed. Lincoln,RI,US: QualityMetric Incorporated; 2001.

18. Tuomi K, Ilmarinen J:,A., Katajarinne L, Tulkki A. The Work Ability Index (WAI). Occupational Medicine. 2007;57(2):160.

19. Kauhanen J, Julkunen J, Salonen JT. Coping with inner feelings and stress: Heavy alcohol use in the context of alexithymia. Behav Med. 1992;18(3):121-126.

20. McCaffery M, Beebe A. Pain: Clinical manual for nursing practice. St.Louis, MO: Mosby; 1989. 353 p.

21. Hawker GA, Mian S, Kendzerska T, French M. Measures of adult pain: Visual analog scale for pain (VAS pain), numeric rating scale for pain (NRS pain), McGill pain questionnaire (MPQ), short-form McGill pain questionnaire (SF-MPQ), chronic pain grade scale (CPGS), short form-36 bodily pain scale (SF-36 BPS), and measure of intermittent and constant osteoarthritis pain (ICOAP). Arthritis Care Res. 2011;63(11):240-252.

22. Riise T, Moen BE, Nortvedt MW. Occupation, lifestyle factors and health-related quality of life: The hordaland health study. J Occup Environ Med. 2003;45(3):324-332.

23. Wendel-Vos GC, Schuit AJ, Tijhuis MA, Kromhout D. Leisure time physical activity and health-related quality of life: Cross-sectional and longitudinal associations. Qual Life Res. 2004;13(3):667-677.

This article is protected by copyright. All rights reserved. 
24. Vuillemin A, Boini S, Bertrais S, et al. Leisure time physical activity and health-related quality of life. Prev Med. 2005;41(2):562-569.

25. Nakamura PM, Teixeira IP, Smirmaul BP, et al. Health related quality of life is differently associated with leisure-time physical activity intensities according to gender: A cross-sectional approach. Health Qual Life Outcomes. 2014;12(98). doi: 10.1186/1477-7525-12-98.

26. Jurakic D, Pedisic Z, Greblo Z. Physical activity in different domains and health-related quality of life: A population-based study. Qual Life Res. 2010;19(9):1303-1309.

27. Chau JY, Grunseit AC, Chey T, et al. Daily sitting time and all-cause mortality: A metaanalysis. PLoS One. 2013;8(11). doi:10.1371/journal.pone.0080000

28. Biswas A, Oh PI, Faulkner GE, et al. Sedentary time and its association with risk for disease incidence, mortality, and hospitalization in adults: A systematic review and meta-analysis. Ann Intern Med. 2015;162(2):123-132.

29. Omorou AY, Vuillemin A, Menai M, et al. 10-year cumulative and bidirectional associations of domain-specific physical activity and sedentary behaviour with healthrelated quality of life in french adults: Results from the SU.VI.MAX studies. Prev Med. 2016;88:66-72.

30. Balboa-Castillo T, Leon-Munoz LM, Graciani A, Rodriguez-Artalejo F, Guallar-Castillon P. Longitudinal association of physical activity and sedentary behavior during leisure time with health-related quality of life in community-dwelling older adults. Health Qual Life Outcomes. 2011;9(47). doi: 10.1186/1477-7525-9-47.

This article is protected by copyright. All rights reserved. 
31. Meneguci J, Sasaki JE, Santos A, Scatena LM, Damiao R. Sitting time and quality of life in older adults: A population-based study. J Phys Act Health. 2015;12(11):1513-1519.

32. Scott KA, Browning RC. Occupational physical activity assessment for chronic disease prevention and management: A review of methods for both occupational health practitioners and researchers. J Occup Environ Hyg. 2016;13(6):451-463.

33. Nenonen N. Analysing factors related to slipping, stumbling, and falling accidents at work: Application of data mining methods to finnish occupational accidents and diseases statistics database. Appl Ergon. 2013;44(2):215-224.

34. Holtermann A, Marott JL, Gyntelberg F, et al. Occupational and leisure time physical activity: Risk of all-cause mortality and myocardial infarction in the copenhagen city heart study. A prospective cohort study. BMJ Open. 2012;2(1). doi: 10.1136/bmjopen2011-000556.

35. Penedo FJ, Dahn JR. Exercise and well-being: A review of mental and physical health benefits associated with physical activity. Curr Opin Psychiatry. 2005;18(2):189-193.

36. van den Berg TI, Alavinia SM, Bredt FJ, Lindeboom D, Elders LA, Burdorf A. The influence of psychosocial factors at work and life style on health and work ability among professional workers. Int Arch Occup Environ Health. 2008;81(8):1029-1036.

37. Schuring M, Burdorf L, Kunst A, Mackenbach J. The effects of ill health on entering and maintaining paid employment: Evidence in european countries. J Epidemiol Community Health. 2007;61(7):597-604.

This article is protected by copyright. All rights reserved. 
38. Mansoubi M, Pearson N, Biddle SJ, Clemes S. The relationship between sedentary behaviour and physical activity in adults: A systematic review. Prev Med. 2014;69:2835.

39. Knuth AG, Hallal PC. Temporal trends in physical activity: A systematic review. J Phys Act Health. 2009;6(5):548-559.

40. Romeis JC, Heath AC, Xian H, et al. Heritability of SF-36 among middle-age, middleclass, male-male twins. Med Care. 2005;43(11):1147-1154.

41. Bauman A, Ainsworth BE, Bull F, et al. Progress and pitfalls in the use of the international physical activity questionnaire (IPAQ) for adult physical activity surveillance. J Phys Act Health. 2009;6(1):5-8.

This article is protected by copyright. All rights reserved. 


\section{Figure captions}

Figure 1. Distribution of total PA (MET-h/week). The box shows the distance between the quartiles, with the median marked as a line and the whiskers showing the 5th and 95th percentiles. Dashed lines divide the tertiles (Lowest, Middle, Highest).

Figure 2. Relative MET-h/week (\%) according to PA tertiles of total PA and average sitting time (h/day) (with 95\% confidence interval) in physical activity domains (IPAQ).

Figure 3. Age- and employment status-adjusted mean (with $95 \%$ of confidence interval) profiles in health related quality of life (SF-36) dimensions between the tertiles. $\mathbf{m}=$ Lowest, $\bullet=$ Middle and $\circ=$ Highest tertile. The $p$-value indicates linearity across the tertiles.

Figure 4. Relationships between IPAQ domains and health-related quality of life according to physical and mental component summary. $\beta$-values with $95 \%$ confidence intervals.

This article is protected by copyright. All rights reserved. 
Table 1. Demographic and clinical characteristics of the participants $(\mathrm{N}=1278)$ divided into tertiles according to level of physical activity (MET-h/week).

\begin{tabular}{|c|c|c|c|c|}
\hline & $\begin{array}{l}\text { Lowest } \\
(n=426)\end{array}$ & $\begin{array}{l}\text { Middle } \\
(\mathrm{n}=425)\end{array}$ & $\begin{array}{l}\text { Highest } \\
(\mathrm{n}=427)\end{array}$ & $\begin{array}{l}\text { P-value for } \\
\text { linearity }\end{array}$ \\
\hline Age, mean (SD) & $32(7)$ & $31(7)$ & $30(7)$ & 0.002 \\
\hline BMI, mean (SD) & $26.3(4.3)$ & $25.9(3.7)$ & $26.1(4.0)$ & 0.39 \\
\hline $\mathrm{BMI} \geq 30.0, \mathrm{n}(\%)$ & $63(15)$ & $56(13)$ & $61(14)$ & 0.79 \\
\hline Status, n (\%) & & & & $<0.001$ \\
\hline Employed & $284(67)$ & $310(73)$ & $374(88)$ & \\
\hline Student & $73(17)$ & $74(17)$ & $25(6)$ & \\
\hline Unemployed & $53(12)$ & $32(8)$ & $26(6)$ & \\
\hline Disability pension & $14(3)$ & $8(2)$ & $2(1)$ & \\
\hline \multicolumn{5}{|l|}{ Disorders, n (\%) } \\
\hline Accidents & $38(9)$ & $36(8)$ & $58(14)$ & 0.025 \\
\hline $\begin{array}{l}\text { Musculoskeletal } \\
\text { disorders }\end{array}$ & $85(20)$ & $65(15)$ & $89(21)$ & 0.083 \\
\hline $\begin{array}{l}\text { Cardiovascular } \\
\text { disorders }\end{array}$ & $23(5)$ & $8(2)$ & $11(3)$ & 0.10 \\
\hline Lung disorders & $21(5)$ & $18(4)$ & $26(6)$ & 0.46 \\
\hline Mental disorders & $36(8)$ & $13(3)$ & $25(6)$ & 0.003 \\
\hline $\begin{array}{l}\text { Alcohol consumption, } \\
\text { (dose per/week } \\
\text { median, IQR) }\end{array}$ & $4(1,10)$ & $4(1,10)$ & $4(1,10)$ & 0.56 \\
\hline Pain, NRS, mean (SD) & $1.6(1.9)$ & $1.4(1.9)$ & $2.0(2.2)$ & $<0.001$ \\
\hline Low back pain, $N R S \geq 4$ & $73(17)$ & $70(16)$ & $108(25)$ & $<0.001$ \\
\hline $\begin{array}{l}\text { Lower limb pain, } \\
\qquad \mathrm{NRS} \geq 4\end{array}$ & $47(11)$ & $50(12)$ & $69(16)$ & 0.055 \\
\hline Neck pain, NRS $\geq 4$ & $78(18)$ & $58(14)$ & $104(24)$ & $<0.001$ \\
\hline $\begin{array}{c}\text { Upper limb pain, } \\
\qquad \mathrm{NRS} \geq 4\end{array}$ & $51(12)$ & $51(12)$ & $67(16)$ & 0.18 \\
\hline
\end{tabular}

Values are means (SD) or $\mathrm{n}(\%)$ unless otherwise noted.

$\mathrm{IQR}=$ interquartile range

NRS = numeric rating scale

This article is protected by copyright. All rights reserved. 
Table 2. PA domains expressed as MET-h/week and sitting time as h/day in each tertile.

\begin{tabular}{lcccc}
\hline & $\begin{array}{c}\text { Lowest } \\
(<38)\end{array}$ & $\begin{array}{c}\text { Middle } \\
(>38<100)\end{array}$ & $\begin{array}{c}\text { Highest } \\
(>100)\end{array}$ & \\
IP=426 & $\mathrm{n}=425$ & $\mathrm{n}=427$ & P-value for \\
Mean (SD) & Mean (SD) & Mean (SD) & linearity \\
\hline Work & $3(6)$ & $19(24)$ & $129(66)$ & $<0.001$ \\
Active transportation & $5(6)$ & $12(13)$ & $19(23)$ & $<0.001$ \\
Domestic and & $9(14)$ & $16(23)$ & $29(36)$ & $<0.001$ \\
gardening & & & $38(42)$ & $<0.001$ \\
Leisure time & $9(9)$ & $29(21)$ & $5(3)$ & $<0.001$ \\
Sitting (h/day) & $8(3)$ & $7(3)$ & & \\
\hline
\end{tabular}

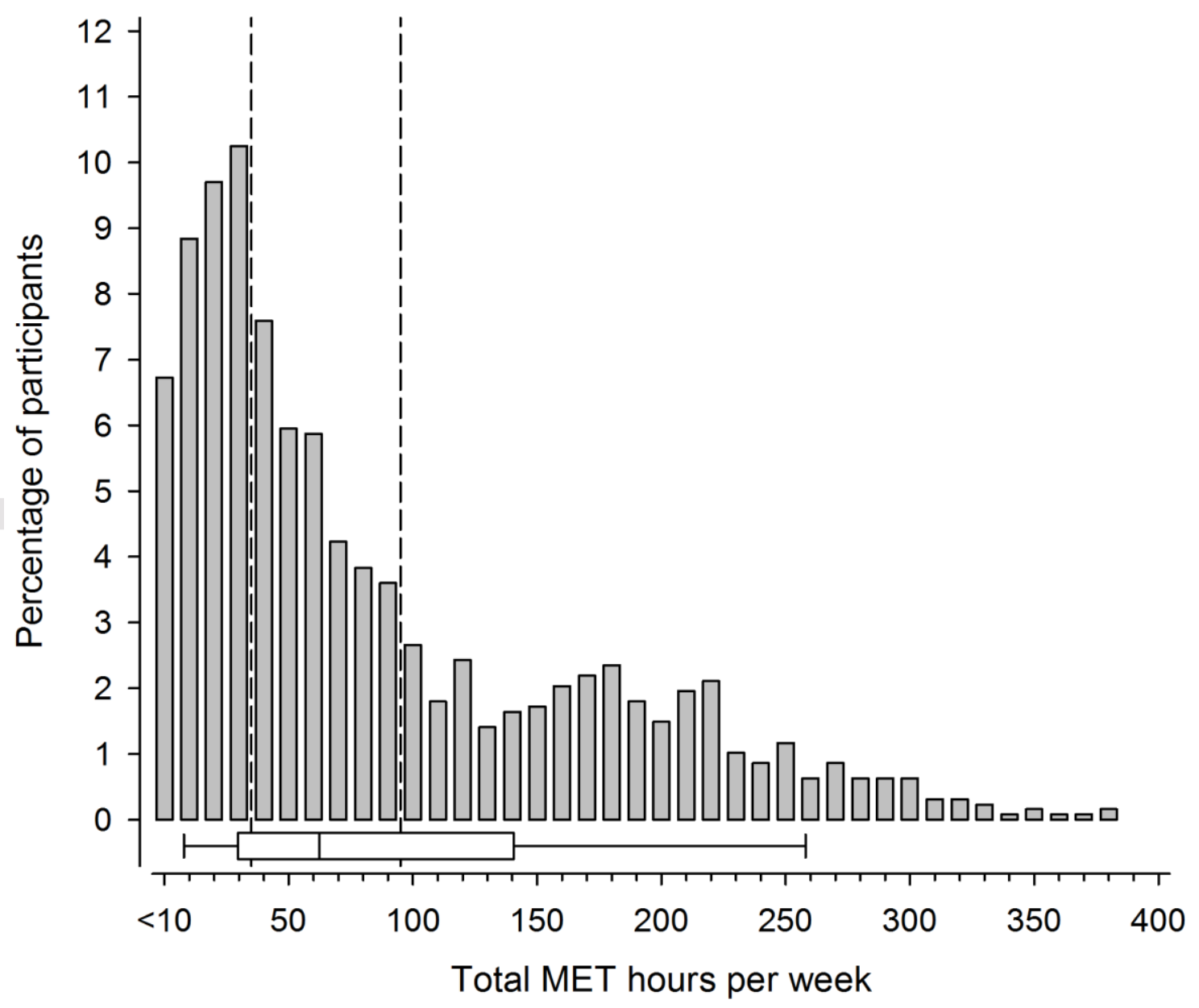

This article is protected by copyright. All rights reserved. 


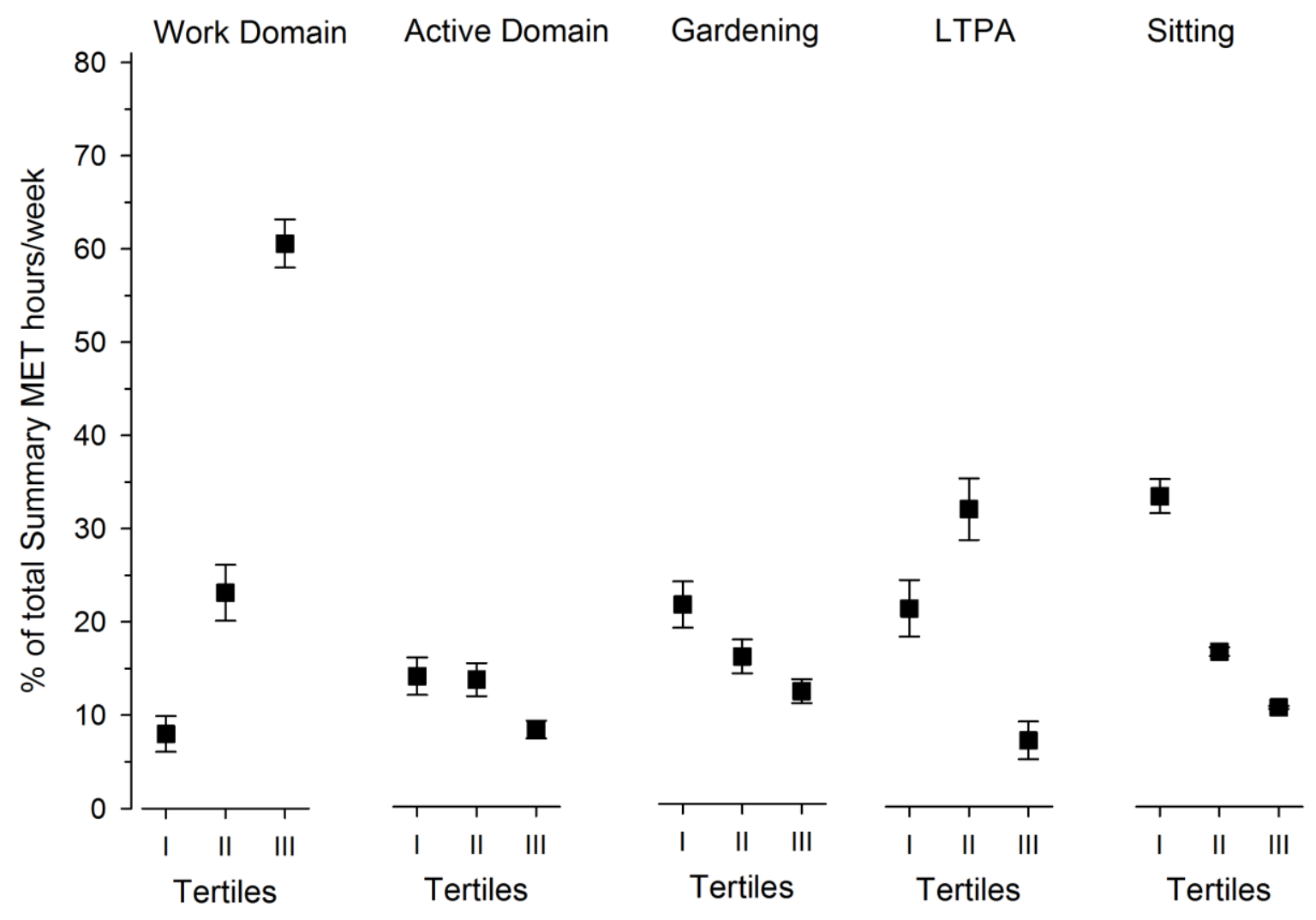

This article is protected by copyright. All rights reserved. 


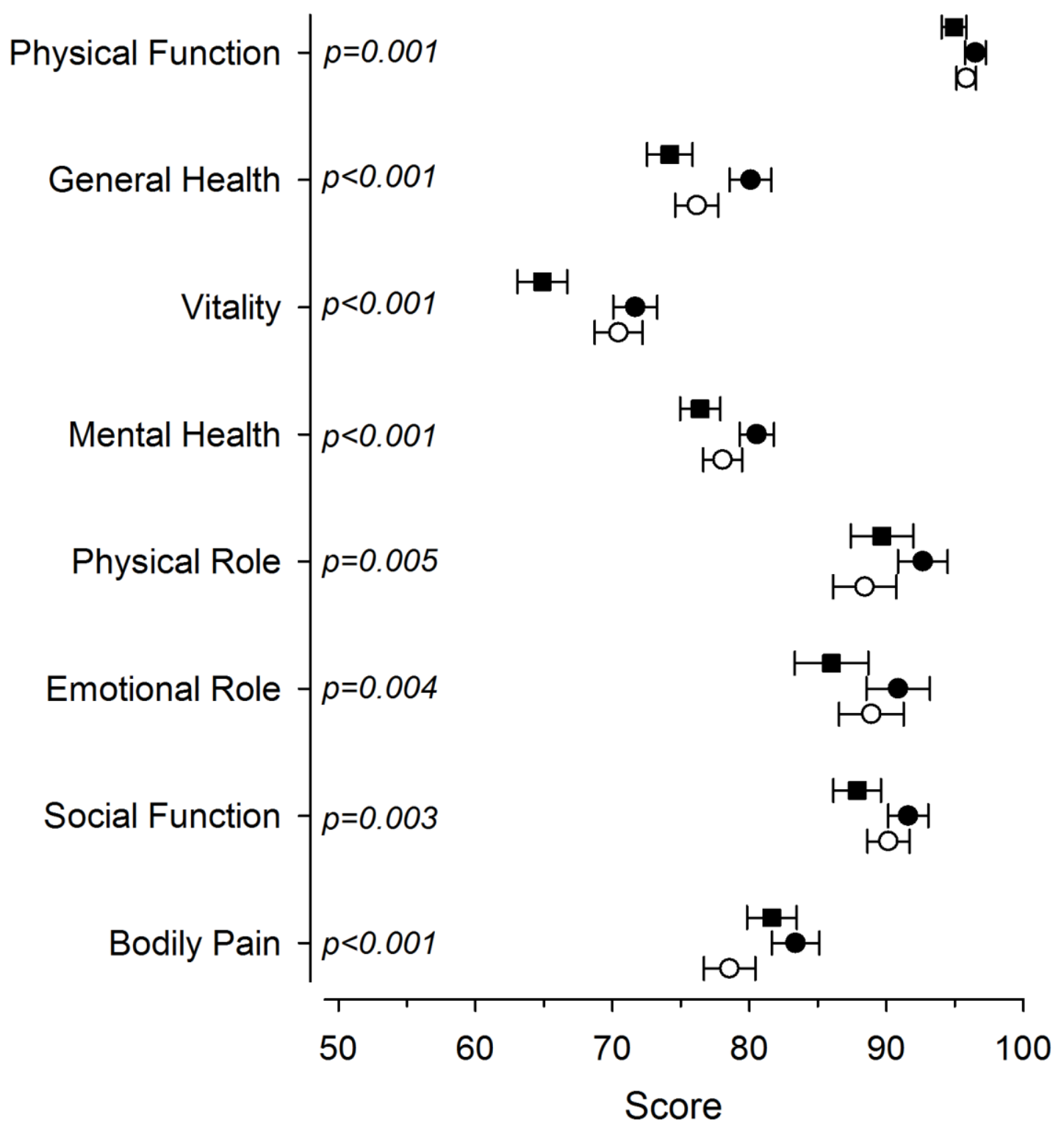




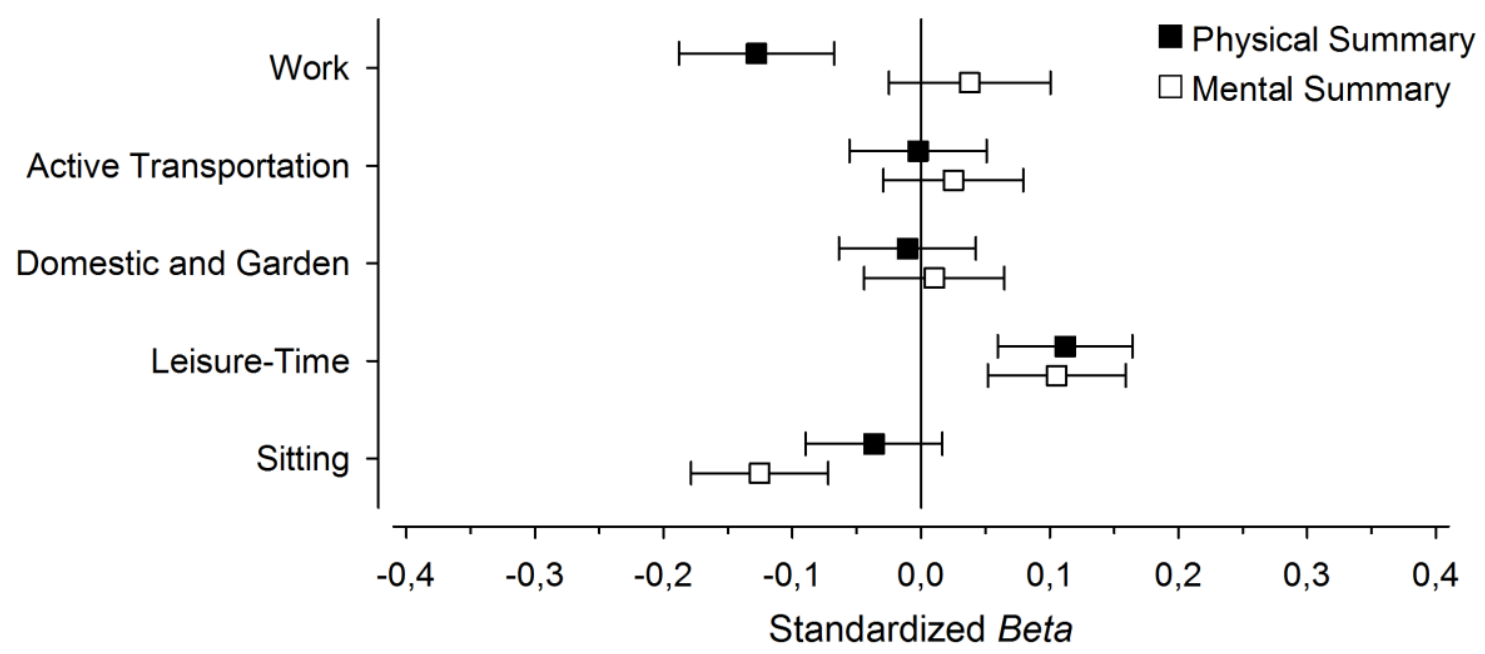

This article is protected by copyright. All rights reserved. 